\title{
The Main Responsibility and Reinforcement Strategy of Government in Emergency Communication Management ${ }^{*}$
}

\author{
HU Xiao-juan \\ Dalian University of Technology, Dalian, China
}

\begin{abstract}
In modern state management system, "as the provider of public services, the maker of public policies, the manager of public affairs and the executor of public power, the government has the obligation to assume the main responsibility in emergencies" (Wang, 2010). China's Constitution, Emergency Response Law of the People's Republic of China, and other laws have clarified the legal responsibility of the government in emergency response. The degree and effect of the government's responsibility fulfillment determine whether emergency response successes or not. The government should fully fulfill its responsibility in emergency communication and management, innovate social governance, guarantee the right to know, strengthen public opinion guidance, and improve the ability to deal with the media.
\end{abstract}

Keywords: emergency, government, media, the right to know, public opinion guidance

\section{Government' Main Responsibility in Emergency Communication Management Protecting Citizens' Right to Know}

Right to know was first raised in 1945 by Associated Press editor Kent Cooper, which means the right to know and understand. Although academic circles have different interpretations on the concept of right to know, they highly agree that citizens should have the right to request information disclosure according to law. Wiggins, an American expert on the right to know, believes that the right to know should contain at least five basic rights, among which "the right to gain information" is the most important (Zhang \& Lv, 2002).

China's Constitution protects citizens' right to know and puts it into practice in government information disclosure. Releasing information to the public in a timely and accurate manner whenever an emergency occurs is the concentrated embodiment of the government's responsibility. Emergencies are naturally high-risk and unstable, with large and concentrated information, which are closely related to the interests of the public. Therefore, the government and the media must release relevant information comprehensively, timely, and accurately to meet the public's right to know.

Practice has proved that information disclosure has become a key measure for the government to deal with emergencies. The government should proceed from reality of stabilizing the society, maintaining security, and preventing the crisis from escalating, and inform the truth in time, so as to better safeguard public interests.

\footnotetext{
*Acknowledgements: This paper is fund by Dalian Social Science Federation "The Main Responsibilities of Government in Emergencies From the Perspective of Social Governance-A Case Study of Dalian (2018dlskzd030)".

HU Xiao-juan, Ph.D., Lecturer, Master supervisor, Department of Humanities and Social Sciences, Dalian University of Technology, Dalian, China.
} 


\section{Timely Providing Real and Accurate Information to the Media}

Mature practice and experience of the developed countries shows that the government needs to occupy a dominant position dealing with emergencies, at the same time appreciate the role of the media. In addition, the government should help media and social other department work closely to arouse the enthusiasm of all parties, and win broad understanding, cooperation, and support.

Media plays an important role in emergencies. As a bridge and link between the government and the public, media usually obtains authoritative information from the government as soon as an emergency occurs, and then first time transmits to the public, so as to facilitate them to understand the truth and government behavior (Zhang, 2009).

In emergencies, media has not peasants out of "aphasia". Due to political, economic, or certain public opinion pressure, the media has no choice but to do. However, this traditional and habitual practice of suppressing public opinion through public power is ridiculous and unworkable in the era of new media. Blindly shield and dodge, hoping to achieve media security through media aphasia will not work. On the contrary, it will make things worse, leading to greater crisis and chaos. Nowadays information dissemination means are so developed that trying to hide or restrict information is impractical. Only by making information transparent can rumors be suppressed at the source.

\section{Actively Guiding Public Opinion Through the Media}

Media plays a vital role in the evolution of emergencies. The social utility attribute of media makes it an unshirkable responsibility for the prevention of public crisis.

Under the new media environment, emergencies become the biggest hidden danger of social security. "We media" presents the characteristic of "decentralization". Everyone has a microphone and can spread information, which breaks the monopoly of traditional media in news transmission. The communication effect is difficult to control, and the lack of checking and controlling will inevitably lead to increased risks in communication.

Therefore, public opinion guidance is the government's top priority in handling with emergencies. The key to the government's correct handling of emergencies is to properly handle the relationship with the media.

The United States, Britain, Germany, Japan, and other countries have done a good job in handling emergencies with the help of the publicity ability of the media, creating a good social atmosphere, correctly guiding public opinion, and preventing the spread of rumors (Zhang, 2013).

The British government believes that if emergencies are handled properly, the media can calm the public mood, maintain social stability, and help the government quickly convey important information and instructions to the public. Therefore, the British government attaches great importance to the ability of the government to deal with the media in an emergency.

According to the regulations of the British government, relevant departments are obliged to provide timely and accurate information to the media and cooperate effectively with the media in an emergency. The government has also signed an agreement with the media to suspend media programs and release accident data and safety guidance in the event of a serious emergency. The British government has been preparing for an emergency media response in discussions and exercises.

\section{How to Reinforce the Government's Ability to Deal With Emergencies}

With continuous improvement of the legal system, the communication and management practices of emergencies have become increasingly rich. However there are still some problems. 
The government usually sets up temporary institutions to deal with problems encounter emergencies, lacking relevant "coordination mechanism" and "accountability mechanism", which leads to insufficient coordination among various departments. After the crisis, the temporary institutions also withdraw, lacking standardization, institutionalization, and scientization. Chen Yong'an pointed out that in order to cope with complex and changeable emergencies, government urgently needs to establish an emergency management system (Chen, 2003).

Existing laws and regulations still need to be further implemented and improved, for example, the depth and breadth of government information disclosure is not enough, the concept has not been solidified, and the level of legislation is low $(\mathrm{Gu}, 2010)$.

In fact, the government has not fully grasped the dominant right of information disclosure, and there are still improper acts of avoiding, concealing, and blocking information. The timeliness of information disclosure is difficult to guarantee, and the effect of information disclosure is difficult to meet public expectations. Meanwhile, in view of some media's deliberate incitement, excessive commercialization, and violation of journalistic ethics, the government also needs timely supervision.

More importantly, the government's press release procedures are not standardized. At present, news release has not been normalized and institutionalized. In addition, there are also a lot of problems with spokesman, such as uneven quality; the number is far from enough. So the government ability to deal with the media needs to be improved.

In Europe, government press releases are normalized and institutionalized. European countries usually regard press release as a highly specialized profession, valuing financial and personnel support (Cheng, 2010).

In the United States, a series of legal systems have been adopted to improve the rules of press release. The idea of "sovereignty in the people" has been adopted to satisfy the public's right to know and build a good government image. In addition, the level of government news release in the United States is perfect, covering all levels of government departments from the federal government to the state government and then to all levels. News release means are flexible and diverse, including not only traditional news conferences, press conferences, and news briefings, but also timely release through the Internet and organizing journalists to follow the group interview (Li, 2007).

In view of the above problems, the government still needs to actively improve and innovate social governance and respond to emergencies.

\section{Clear Responsibilities, Control Contents, Enrich Methods, and Improve Effects}

Firstly, we should establish and improve the emergency management system with clear rights and responsibilities, improve the efficiency and quality of information disclosure, and clarify the main responsibility.

Secondly, it is necessary to strictly control the source of information in order to ensure authenticity and reliability and strengthen the audit of information process to ensure the authority of government.

Also, enriching the means of information disclosure such as portal website, official micro-blog, and wechat, is also important for protecting citizens' right to know.

Finally, we should ensure the effect of information disclosure and realize the effective connection between supply and demand. The ungrounded way of information expression can no longer meet the public expectation. The government should adopt an expression that is in line with public opinion, focusing on the issues of the 
public's most concern, thinking what the public wants and what the public needs. In terms of discourse expression, try to be popular and provide targeted services to meet the needs according to the feedback.

In short, the government needs to formulate detailed rules and management measures for information flow in public emergencies and establish a quick response communication mechanism to ensure the efficiency and quality of information disclosure.

\section{Improve the Ability to Deal With the Media and Make Concerted Efforts}

Effective information transmission in emergencies is of vital importance, which requires the media to guide public opinion and stabilize people's mind. The government must be the first to respond to ensure that information flows quickly. Government departments should meet the needs of the media in information release and win the trust of the people with the help of media thinking.

The government still needs to further improve its ability to deal with the media, especially in response to emergencies. It is urgent to standardize the press release and intensify efforts to train news spokesmen.

In the future, it is necessary to establish an information dissemination system, further standardize the links and principles of information release and dissemination in emergencies, and make the operation of government officials legal. Certainly, it is encouraging to hire media communication consultants to give more guidance from a professional perspective. Through daily case study and business training, media literacy also can be constantly improved. The government needs to understand new communication formats and technologies, master communication characteristics and rules of different media, learn successful experience through typical cases, summarize the lessons from failures, and enhance the actual combat coping ability (Chen, 2013).

The government should guide coherent units to strengthen communication and contact with the media. On one hand, it can create an authoritative information platform, form a three-dimensional situation, actively provide information sources to the media, adhere to the principle of "golden 4-hour", "tell the truth, say it immediately", and provide policy support for the media. On the other hand, the government should also make use of the media and guide public opinion to develop in favor of handling emergencies. In addition, experts, scholars, opinion leaders, and public relations companies can also be used to actively carry out crisis public relations (Yuan \& Zuo, 2013).

\section{Early Warning of Emergencies, Initiative Speaking Up, and Active Guiding Public Opinion}

From the perspective of crisis management, the government is the main body of public emergency management, and doing a good job of public opinion guidance is the top priority of government emergency disposal.

First of all, the government should strengthen its own construction and implement daily public opinion warning for good watch prevents misfortune, that is to say, to normalize the management of public emergencies. Relevant measures include implementing relevant laws and regulations, improving the monitoring mechanism for the context of public opinions, enhancing the credibility of the government, and expanding the path of public opinion guidance.

In the second place, the government should take responsibility initiatively and actively respond to public opinion. Attitude is more important than ability facing with emergencies. The government must respect and protect the public's right to know.

In addition, the government can take advantage of big data to analyze and guide public opinion. Faced with massive network information, big data, data mining, and other information technologies can improve the 
efficiency and accuracy of public opinion analysis. For example, capture network public opinions through Python, identify topics through TF-IDF, sort subject words and emotional words through emotional word list, and gradually improve the ability to deal with public opinions in emergencies.

\section{Conclusion}

The government's leading position in public security emergencies is very important. The degree and effect of its responsibility fulfillment determines the success or failure of emergency response. The government still needs to actively improve and innovate social governance to respond to the communication and management of emergencies.

Social governance practice has a long history; however, as a theoretical study, it began in the 1990s. Future study may concentrate on the responsibility and problems of government emergency communication management from the perspective of social governance, which will emphasize the participation of multiple subjects to form symbiotic relationship of equal cooperation. The "all for all service" will weaken the vertical color in information dissemination, promote the flattening development of the society, ensure timely flow of information, and improve the openness and transparency of information. The effective dissemination of information plays an important role in social governance. In consequence, it will accelerate the formation of social synergy, reduce communication costs, narrow differences, eliminate estrangement, and reduce anxiety.

\section{References}

Chen, M. (2013). Study on public opinion guidance of government response to emergencies (Doctoral thesis of Huazhong University of Science and Technology).

Chen, Y. A. (2003). Consideration on the establishment of emergency management system for government. Journal of Yunnan Administration College, 4, 20-23.

Cheng, M. L. (2010). Enlightenment of press release system of three European countries. Journalists, 7, 62-64.

Gu, J. G. (2010). Problems and countermeasures of government information disclosure. Information Science, 6, 834-836.

Li, X. H. (2007). Research on the press release system of the Chinese government (Doctoral dissertation of Fudan University).

Wang, Z. G. (2010). Analysis of government response strategies to emergencies. Journal of Liaoning Institute of Socialism, 1 , 93-96.

Yuan, Z. L., \& Zuo, X. Y. (2013). The strategy selection of public opinion guidance for emergencies in omnimediaera. Socialist Research, 2, 121.

Zhang, C. M. (2009). Information transmission and media response of the government in public emergencies. Management Science, 4, 42-43.

Zhang, Q. F., \& Lv, Y. B. (2002). Theory about right to know. Journal of Jiangsu Administration Institute, 3, 106-108.

Zhang, Y. (2013). Brief analysis of the importance of optimizing the relationship between the government and the media in emergencies. Manager, 11, 269. 